\begin{tabular}{|c|c|c|}
\hline $\mathrm{PKS}$ & REVISTA DE GEOGRAFIA & OJS \\
\hline $\begin{array}{l}\overline{\text { PUBLIC }} \\
\text { KNOWLEDGE } \\
\text { PROJECT }\end{array}$ & $\begin{array}{c}\text { (RECIFE) } \\
\text { http://www.revista.ufpe.br/revistageografia }\end{array}$ & $\begin{array}{l}\text { OPEN } \\
\text { JOURNAL } \\
\text { SYSTEMS }\end{array}$ \\
\hline
\end{tabular}

\title{
TÓPICOS METODOLÓGICOS PARA A HISTORIOGRAFIA DA GEOGRAFIA
}

\author{
Nilson Cortez Crocia de Barros ${ }^{1}$ \\ ${ }^{1}$ Professor do Departamento de Geografia da Universidade Federal de Pernanbuco.Email: nccrocia@ ufpe.br
}

Artigo recebido em 27/06/2017 e aceito em 17/08/2017

\section{RESUMO}

$\mathrm{O}$ artigo consiste na exposição de alguns tópicos de reflexão considerados relevantes do ponto de vista metodológico para aqueles que se propõem a reconstruir episódios da História da Geografia. $\mathrm{O}$ artigo adota uma perspectiva historiográfica sistemática.

Palavras-chave: História da Geografia; Metodologia historiográfica.

\section{METHODOLOGICAL POINTS TO THE WRITTING OF THE HISTORY OF GEOGRAPHY}

\begin{abstract}
The paper presents some points considered important methodologically for those who intend to write about episodes of the History of Geography. It adopts a systematic historiographic perspective.

Key-words: history of geographical thought; historiographic methodology.
\end{abstract}

\section{INTRODUÇÃO}

O propósito do presente Artigo é expor, de forma concisa, algumas reflexões que acreditamos possam elas ser úteis ao trabalho historiográfico, quer dizer, ao esforço de reconstruir o passado da Geografia, especialmente quando do episódio da sua difusão ou espalhamento pelo mundo extra europeu.

Poucos assuntos se mostram tão controversos e possuem interpretações tão competitivas entre si quanto a longa história da ciência denominada Geografia. A sua origem recuada pelo menos até às experiências chinesa e greco-romana, a vastidão dos assuntos que ela sempre ousou abranger, os desafios que enfrentou com o progresso das especializações saídas de dentro do seu próprio campo comum, a sua intimidade ora com os fenômenos puramente extra-humanos como a tectônica, ora com os assuntos de ordem histórica e moral, 
a sua relevância junto aos poderes de estado, tudo isto preanuncia a complexidade a ser enfrentada pelo historiador da Geografia.

A aproximação, portanto, deste objeto de pesquisa, quer dizer, da História da Geografia, postula naturalmente algumas reflexões prévias ou considerações sistemáticas sobre o próprio ato a empreender, que é precisamente o de reconstruir os passos dados pelo ramo do saber. Os itens metodológicos historiográficos a seguir apresentados, evidentemente, constituem uma listagem tentativa, sugestiva e incompleta, e as considerações que são tecidas em cada tópico forçosamente necessitam ampliações e requerem continuados desenvolvimentos críticos.

\section{A HISTORIOGRAFIA DA GEOGRAFIA TORNOU-SE SISTEMÁTICA.}

A partir do final dos anos de 1970 a historiografia da Geografia foi consistentemente adquirindo uma conformação sistemática. Quer-se com isto dizer que as preocupações teóricas e conceituais bem peculiares ao campo da história das ciências inundaram os ambientes de reflexões daqueles que se propunham a contar a História da disciplina.

O estilo historiográfico doutrinário e de afirmação orgulhosa da identidade disciplinar ante os outros ramos do saber, que havia dominado o cenário historiográfico da Geografia desde as primeiras décadas do século 20, quando a disciplina lutava renhidamente para ocupar espaços institucionais nos ambientes do ensino e da pesquisa, recuou. Tal estilo cedeu lugar às análises ora mais radicalmente contextuais - sociologizadas - ora propriamente combinatórias, neste último caso contemplando, em doses variáveis, as apreciações contextual e epistemológica.

Identificam-se os denominados estudos culturais críticos da década de 1970 como estimuladores deste rápido processo de alteração nos padrões da historiografia da Geografia. Lia Machado (MACHADO, 2003, p.314) identificou este novo estilo de contar a formação da disciplina. A História da Geografia, então, nos tempos pós-modernos, desnudou-se do aspecto natural e evolutivo com o qual vinha sendo contada ora em manuais de ensino ora nos estudos eruditos, de modo que as peças historiográficas atuais veem a formação da disciplina distanciadas da paixão geográfica doutrinária (BARROS, 2006). Mas, em passado recente, a historiografia doutrinária havia ou reforçado a tradição regional - como no célebre The Nature of Geography de R. Hartshorne - ou suportado apelos de mudanças, e, casos extremos, de revolução, como reza o rústico artigo crítico-radical de Schaeffer 
(Excepcionalism in Geography), oriundo da socialdemocracia sindical metalúrgica alemã (esquerda).

Parte considerável da historiografia da Geografia incorpora às suas análises a ideia contextual da expansão dos imperialismos industriais. Em outras palavras, a historiografia reconhece o fato de que a Geografia cooperou, ao seu modo, na modernização do mundo - e evidentemente no desmantelamento dos espaços geográficos tradicionais - perpetrada pelos imperialismos europeus e seus enclaves no além-mar. Entendemos que esta é de fato a realidade positiva historiográfica mais fértil e abrangente, sendo irrelevantes, historiograficamente, supostas filiações ideológicas - i. é, diferentes mentalidades imperialistas - declaradas ou não pelos geógrafos à época protagonistas-praticantes (BARROS, 2012 a, b, 2016).

\section{OS NÓdULOS, OS ESPAÇOS RELACIONAIS E AS ALTERAÇÕES NO CARÁTER DA GEOGRAFIA.}

É decisiva a influência exercida pelos sítios culturais (nódulos) e suas redes na construção da Geografia (DUNCAN \& LEY, 1993; LIVINGSTONE, 1992, 2003). Uma vez isto reconhecido, prossegue que a historiografia está sempre atenta às interatividades que conectam os efetivos locais da produção da disciplina, quer dizer, os locais onde a disciplina é de fato praticada. Embora não desconhecendo aquilo que os contornos ou contextos regionais amplos convencionais (continentes, nações, regiões) possam oferecer de elucidativo para o entendimento das experiências da construção da disciplina, a orientação analítica foca as circularidades entre aqueles locais (escritórios, instituições de ensino, eventos, etc) que formam um meio ou espaço de relações ou relacional.

O centro das mudanças nos estilos das ciências - não obstante o papel ativo exercido sobre elas pelos contextos políticos gerais nacionais - repousaria nos ambientes específicos do trabalho geográfico, locais chamados de nódulos: as Casas da Sabedoria no Islã (BARROS, 2005), as Academias greco-romanas, os Clubes de Viagens que surgiram na Era dos Descobrimentos na Europa depois transformados alguns em honorárias Sociedades Geográficas, as repartições públicas imperiais, os institutos histórico-geográficos, as antigas instituições escolares de ensino médio e superior com as suas cátedras disputadas mediante defesas públicas de teses - a exemplo dos tradicionais colégios do Brasil, como o Ginásio Pernambucano, no Recife, e tradicionais Faculdades -, nos escritórios de pesquisa e 
planejamento de consultorias e organismos multilaterais (Banco Mundial, por exemplo), nas universidades, nos institutos de pesquisa atuantes em escalas diversas (nacional, estadual, municipal), nas equipes em expedições de campo, etc.

Exemplo da historiografia que reconhece a proeminência dos nódulos e redes assim definidos é o trabalho de Barnes \& Farish (2006). Eles investigaram mudanças imprimidas ao conceito de região que tiveram lugar nos novos nódulos e suas redes - (ambientes) institucionais - globais criadas pela Guerra Fria. As mudanças nos padrões de Geografia aconteceriam nestes nódulos e suas ligações; tal conjunto formaria um sistema profissionalmente estimulado, provido de vantagens financeiras e hierarquicamente posicionado para impor prestigiosamente suas inovações de estilo. Então, neste ambiente, neste meio institucional, ocorreria o processo que Pickering (1995, p.5, cit. por BARNES \& FARISH, 2006, p.809) denominou de compressão (ou "mangling", em Inglês). O termo sugere que nestes ambientes burocráticos se induziriam transformações no pensamento e nas praticas dos agentes aí presentes, deixando-lhes hábitos ou rotinizações metodológicas, conceituais e temáticas.

Estes meios institucionais se sobreporiam às fronteiras nacionais e regionais, lhes seriam mesmo indiferentes, e difundiriam as ideias e práticas que roteirizariam as mudanças nas características disciplinares. Ilustrativamente, lembremos que do ponto de vista epistemológico carece mesmo de relevância distinções entre experiências nacionais de pensamento geográfico, por conta dos tais espaços relacionais. O trabalho de Mércier (1995), por exemplo, sugere isto ao mostrar as semelhanças nas concepções de estado em Frederico Ratzel e P. Vidal de La Blache, não obstante a disseminada superstição historiográfica da suposta "profunda" diferença entre a antropogeografia de língua francesa e de língua alemã. Outro exemplo: o que Delgado de Carvalho difundiu no Brasil assemelha-se ao que MacKinder promoveu na Grã Bretanha (BARROS, 2008) e tem paralelo nas décadas anteriores nas experiências nacionais da França e da Alemanha (ABREU, 2006, p.131). Exemplo das redes burocráticas em edificação e funcionamento foi a vinda dos assessores $\mathrm{P}$. Monbeig e Deffontaines ao Brasil como episódios da mesma cadeia de espalhamento e homogeneização cultural (ABREU, 2006, p.131) da modernização que veio a atingir os principais sítios urbanos culturais do Brasil. 


\section{OS HÁBITOS DE ESCALA NO PENSAMENTO GEOGRÁFICO.}

Lia Machado observou que - do ponto de vista da escala dos interesses e do alcance espacial das cogitações - a Geografia que se difundiu no Brasil esteve voltada para dentro do próprio Território brasileiro, isto é, ela esteve focada na escala nacional, na Escala dos chamados "problemas nacionais" ou "problemas brasileiros". Além disto, em função das dimensões espaciais amplas do Brasil, das diferenças geográficas humanas e físicas verificadas e da memória histórica da afirmação política das identidades provinciais, o fenômeno de percepção, ação e intencionalidade escalar ecoou em alguns sítios culturais periféricos com o hábito do raciocínio escalar regional. Na Região Nordeste do Brasil, em torno da cidade do Recife, por sua posição político-econômica tornada progressivamente periférica no conjunto Território nacional, o assunto escalar se expressará na forma do que passou a ser chamada de A Questão Regional. Em ambos os casos - quer na escala nacional quer na escala regional -, diante da eminencia dos estudos monográficos de área, a escala planetária de observação achava-se no plano secundário, e se pode suscitar a hipótese que em decorrência deste contexto o método positivo comparativo, aquele que conduz à proposição universal e à criatividade teórica, situava-se também secundariamente.

O caráter do olhar exclusivamente para dentro do país - do compromisso com determinada secção de área (nação, província, região) e não com um tópico - fez com que a Geografia moderna no Brasil diferisse da Geografia europeia imperial moderna em foco, embora nela procurasse se espelhar e usar os seus mesmos moldes conceituais. Isto por que, não obstante a preocupação espacial interna aos seus países, o pensamento geográfico moderno no continente europeu manteve um permanente foco nas periferias do além-mar (MACHADO, 2003), nas bordas imperiais. Este olhar para fora se fora construindo pouco a pouco e se constituiu em elemento central da experiência do Iluminismo na ciência dentro dos marcos dos imperialismos europeus.

O olhar para dentro do Brasil soube enfrentar criativamente muitos desafios, nas escalas nacional e regional, inclusive aquele que conduziu ao reciclo crítico do conceito de região, uma vez que as circunstâncias regionais da Europa, que impregnavam a ideia regional, diferiam muito dos amplos espaços e das experiências ambientais, históricas e culturais do continente americano (KIMBLE, 1996). Demoraria tempo - e esforços financeiros, institucionais, educacionais e pessoais consideráveis - para a Geografia brasileira incorporar experiências e perspectivas cognitivas próprias, isto é, senso crítico em relação, por exemplo, 
ao conceito de região; isto se dá particularmente durante o terceiro quartel do século 20, período propriamente identificado como a Idade de Ouro da Geografia no Brasil (DIAS, 1989).

\section{A MOBILIDADE: DESLOCAMENTOS DE CAMPO \& VIAGENS DE ILUMINAÇÃO.}

A longa ontologia da Geografia é inseparável das viagens. Restritivamente, Outram (1999, p.285) e Livingstone (2003, p.42) refletiram sobre a importância historiográfica da experiência da mobilidade ao examinarem as práticas do Iluminismo, e aqui, no presente Artigo, se explora a experiência da viagem na perspectiva da difusão periférica do pensamento geográfico.

No Brasil, o olhar para dentro - expressão do compromisso de conhecer as "realidades" do país - como caráter do pensamento geográfico, diante de um grande território a conhecer, produziu o fenômeno reconhecido na historiografia como a legitimação do geógrafo pelo contato/trabalho de campo - ou pelas visitas in loco - para descrever, narrar as "verdadeiras realidades" (sic) (deslocamento espacial de pesquisa).

O culto deste realismo de espírito viajante vem do final do século XIX, estimulado pelos exemplos das excursões dos vários naturalistas que percorreram o país, e entrou pelo século XX, e institucionalizou-se no período compreendido entre a estruturação do IBGE e os anos de 1950 e começos de 1960, período considerado heroico das explorações e das primeiras peças discursivas geográficas nacionais (DIAS, 1989). No caso da Região Nordeste do país, o "realismo" acaba se institucionalizando mediante a criação da Fundação Joaquim Nabuco (Fundaj) e da Sudene, órgãos públicos ambos situados no Recife, com atribuições de proceder a estudos regionais respectivamente no Norte(Amazônia)/Nordeste.

Neste contexto das explorações e dos levantamentos geográficos das "realidades" nacionais e regionais, a simples ida a locais distantes dos cores - longe das grandes cidades para observações conferia um automático prestígio ao geógrafo. O cientista havia visitado as regiões que ainda "viviam no passado", imersas no "anacronismo", "regiões defeituosas e a consertar", e, enfim, ele retornava ao "presente", às grandes cidades-capitais, melhor dizendo, retornava ao "futuro" para narrar a sua experiência no túnel do "tempo" ou da "evolução". Os "problemas" da cidade advinham do campo, por que lá estava a fonte deles: o passado. Os 
"problemas" eram "trazidos" pelos imigrantes pobres das áreas rurais "atrasadas", e reconhecia-se assim uma relação de conflito expressa no termo campo \& cidade.

O hábito do "realismo" nacional ou regional como uma ideologia racionalizada no trabalho geográfico - hábito adquirido na compressão ("mangling”) da Geografia regional clássica dominante nas décadas dos meados do século $\mathrm{XX}$ - revelou-se cicatriz difícil de ser removida pelas ciências sistemáticas que se propagaram pelo pensamento geográfico no Brasil a partir dos anos de 1960. O realismo de campo, fixado nos anos de 1940 aos anos de 1960, foi usado contra os impulsos teóricos, quer fossem estes impulsos de ordem neopositivista ou histórico-positivistas (marxistas).

Além do deslocamento para o campo, deve-se adicionar mais outra experiência de deslocamento ou viagem, agora específica ao geógrafo nativo das zonas de difusão periférica da Geografia, como o Brasil em geral: o deslocamento à Europa e/ou aos Estados Unidos para apreciar o estado da arte da disciplina, ou para a assimilação das novidades. O fato é que o pensamento geográfico circulava e se difundia pelos sites educacionais e de pesquisa no Brasil por meio das publicações importadas e das atividades de assessores europeus, adicionados os norte-americanos a partir da Segunda Guerra e da Guerra Fria. Então, a eventual e muito rara ida de um geógrafo nativo aos velhos cores da Geografia moderna (Alemanha, França) conferia ao profissional, quase por si só, uma aura de respeito e reconhecimento, pois afirmava-se ter ele "assimilado" diretamente das "fontes" sem necessidade do despacho conceitual, técnico e temático usualmente realizado pelos intelectuais divulgadores intermediários locais.

Delgado de Carvalho, o grande disseminador da Geografia Regional no Brasil, como brasileiro, representa exceção (BARROS, 2008) a esta regra, pois ele chega ao Brasil - tais quais os assessores estrangeiros a partir dos anos de 1930 - após toda uma formação educacional na Europa, e vem também em busca de objeto de pesquisa - e de emprego (SALGUEIRO, 2006, p.195). Na realidade, a experiência da Viagem de Iluminação tem paralelo nos outros países do mundo extra europeu - como o evidencia Speth, no seu estudo sobre a difusão da Geografia nos Estados Unidos (SPETH, 1999) - e naqueles do sul e do leste da Europa.

Entre a primeira metade e meados do século 20, obter formação profissional em centros no exterior era oportunidade praticamente indisponível. A República Velha havia herdado o sistema de patronagem de bolsas, mais propriamente para as Belas Artes e extremamente restritivo, herdado dos tempos generosos do Imperador Pedro II. A verdadeira 
extensão popular, aos vários setores das classes médias e das classes trabalhadoras das grandes cidades, da experiência da exposição internacional na Geografia, viria a ser obra das políticas de ciência e tecnologia da modernização burocrática autoritária de estado pós-1970, amplificada pelo populismo democrático que se seguiu, expandindo-se, assim, oportunidades antes extremamente restritas.

\section{AS ESCOLHAS E OS JULGAMENTOS DE VALOR.}

Os fatos da história de uma ciência não falam por si mesmos. O que acontece de fato é que o historiador escolhe, ele seleciona na ontologia da disciplina, o momento que deseja estudar e trazer aos olhos da sua audiência; ele identifica determinados protagonistas do momento escolhido entre vários outros possíveis profissionais; ele destaca certos textos dentre tantos outros que, por seu turno, ficam na obscuridade; ele aponta os eventos associados que julga relevantes para a hermenêutica textual, deixando outros sem visibilidade alguma; ele hipervaloriza certo(s) texto(s) ou ele superestima uma determinada fase da vida profissional do scholar já por ele mesmo escolhido e minimiza a importância e a relevância d'outros textos ou d'outros momentos profissionais deste mesmo scholar, se apropriando do personagem para a sua causa justo quando o scholar já não pode mais opor nenhuma contestação.

O historiador da disciplina assim age de acordo com os objetivos historiográficos atuais e particulares que ele tenha em mente, objetivos nem sempre explícitos, nem sempre confessados, nem sempre claramente conscientes, mas sempre, para a historiografia sistemática, sujeitos a controvérsias. Ele é guiado, em suma, por julgamentos de valor enquanto seleciona certos fatos, mas ele procede à seleção dos fatos não diante de todos os fatos, simplesmente por que ele não consegue acesso a todos os fatos. É, portanto, aspiração sem sentido pretender, no trabalho historiográfico, produzir uma História que "espelhe" ou "reflita fielmente" os puros fatos ou a ontologia "unificada, progressiva e verdadeira" da disciplina; é possível sim produzir uma representação - reconhecendo-a como uma entre outras competitivas - personalizada, subjetiva e humana de um evento ou experiência da construção da disciplina. 


\section{EXPECTATIVAS, IDEALIZAÇÕES E HARMONIZAÇÕES NA HISTORIOGRAFIA.}

À época da proeminência da historiografia da afirmação disciplinar - antes do ambiente historiográfico pós-moderno -, constituía-se idealização disseminada a crença no aperfeiçoamento progressivo, ascendente e cumulativo da eficiência cognitiva da Geografia, crença grandiosa e abrangente, hoje irrelevante para o trabalho de reconstrução da história da disciplina, a não ser ela própria como objeto de pesquisa. Nutrir, portanto, expectativas de que a ontologia da disciplina possua aquela majestática direção ou sentido ontológico, é uma questão que se reporta ao campo das escolhas e das convicções filosóficas e políticas bem pessoais do historiador.

É do caráter da pesquisa historiográfica possuir, naturalmente, as suas expectativas e as suas idealizações, como o trabalho humano que é, em relação aos fatos, aos personagens, aos textos e às ideias do período em exame, e estas expectativas e idealizações necessitam ser tão identificadas quanto for possível para que se possa agregar às apreciações históricas senso crítico. Tecnicamente falando, dir-se-ia que as análises históricas em muito se beneficiariam da atitude ou disposição de suspender teses e hipóteses ou convicções rotinizadas, isto é, suspender as expectativas e ideias de "estimação" dos historiadores da disciplina.

Sugere-se esta atitude metodológica na historiografia para abrir vão à atitude positiva de permanente exploração e busca de novos significados para os fatos, para as ideias e para os eventos, significados não expectados, valorizando-os, e trazendo-os à narrativa histórica. Isto quer dizer que as narrativas já consolidadas ou habitualizadas - as interpretações "consagradas" ou "reificadas" da historiografia em relação às experiências passadas da disciplina - não devem sufocar as novas perspectivas interpretativas, não devem se sentir totalmente seguras quanto às harmonizações que já produziram e massivamente repetiram, mas sim estarem cientes que há espaços para versões historiográficas competitivas para uma mesma experiência ou episódio da construção da disciplina.

\section{REFERÊNCIAS BIBLIOGRÁFICAS}

ABREU, M.Pierre Monbeig e os primórdios da geografia urbana no Brasil, in: Salgueiro, H. ed., op. cit, 2006, p.129-160. 
AGNEW, J.; LIVINGSTONE, D.; ROGERS, A. (Ed.). Human Geography: an essential anthology. London: Blackwell, 1996.

BARNES, T. ; FARISH, M. Between Regions: Science, Militarism, and American Geography from World War to Cold War. The Annals of The Association of American Geographers, v. 96, n. 4, p. 807-826, 2006.

BARROS, N. Ibn Kaldun, a dinámica dos assentamentos humanos e as funções urbanas no Islã histórico. Mercator, Universidade Federal do Ceará, v. 4, n.8, p. 7-14, 2005.

BARROS, N. Especiação, Região, Progresso e Política Cultural na Antropogeografia de Frederico Ratzel. Geografia, Unesp Rio Claro/Associação de Geografia Teorética (Ageteo), v. 31, n. 3, p. 455-467, 2006.

BARROS, N. Delgado de Carvalho e a Geografia no Brasil como arte da Educação Liberal. Estudos Avançados, IEA/USP, São Paulo, n.62, p.317-334, 2008.

BARROS, N. O geral e o regional na História da Geografia. Revista Geográfica, IPGH/OEA, México, n.152, p.9-30, 2012a .

BARROS, N. Antropogeografia: ecologia, cultura e europeização. Revista de Geografia, Universidade Federal de Pernambuco, v.29, n.2, p. 25-33, 2012 b.

BARROS, N. A modernização da Geografia como Ecologia Humana. In: ALMEIDA, M. \& AZEVEDO, S. (Org.). Diálogos socioambientais e perspectivas culturais. P. Afonso: Editora da Sociedade Brasileira de Ecologia Humana, 2016, p.18-37.

DIAS, L. "La pensée géographique au Brésil: hier et aujourd'hui”, L'Espace Geographique, XVII (3) :193-203, 1989.

DUNBAR, G. (Ed.). Geography: discipline, profession and subject since 1870 - an international survey. The Netherlands: Kluver Academic Publishers, 2001.

DUNCAN, J. The Superorganic in the American Cultural Geography. Annals of The Association of American Geographers, vol.70, n.2, p.181-198, 1980.

DUNCAN, J. \& LEY, D. eds.. "Place, Culture and Representation", London, Routledge, 1993.

KIMBLE, G. The inadequacy of the regional concept. In: AGNEW et al, Human Geography ..., ob. cit., 1996, p. 492-512. (Orig. publicado em 1951).

LIVINGSTONE, D. The Geographical Tradition. London: Blackwell, 1992.

LIVINGSTONE, D. Putting Science in Its Place. Chicago: University of Press, 2003.

LIVINGSTONE, D. ;WHITERS, C. (Eds.). Geography and Enlightnement. Chicago: University Press, 1999. 
MACHADO, Lia O . "Origens do pensamento geográfico no Brasil: meio tropical, espaços vazios e a idéia de ordem (1870-1930)", in: Castro, I.;Gomes, P. \& Correa, R. orgs. Geografia: conceitos e temas. Rio de Janeiro: Bertrand, 2003. p.309-352. (trabalho originalmente datado de 1994).

MÉRCIER, G. La Région et 1’Etat selon Friedrich Ratzel e Paul Vidal de la Blache, Annales de Géographie, $583:$ 211-235, 1995.

OUTRAM, D., "On Being Perseus: New Knowledge, Dislocation, and Enlightenment Exploration", in: Livingstone, D. \& Whiters, C. eds., Geography and Enlightenment, University of Chicago Press, 1999, p.281-294.

PICKERING, A .Cyborg history and the World War II regime. Perspectives in Science, vol.3, n.1, p.1-49, 1995, cit. por Barnes T. \& Farish, M., op.cit, 2006.

SAlguEIRO, H. org. Pierre Monbeig e a geografia humana brasileira. Bauru: Edusc, 2006.

SCHAEFFER, F. Excepcionalismo na Geografia. Boletim de Geografia Teorética, Ageteo/ R.Claro v.7, n.13, p.5-37,1977. (Pub. original Annals of The AAG, 1953)

SPETH, W. How it came to be: Carl Sauer, Franz Boas and the Meanings of Anthropogeography. Washington: Ephemera Press, 1999. 